\title{
FIRST BRAZILIAN CONFERENCE ON STATISTICAL MODELLING IN INSURANCE AND FINANCE
}

The Institute of Mathematics and Statistics of the University of São Paulo is organizing the First Brazilian Conference on Statistical Modelling in Insurance and Finance, to be held from September 1st to September 6th, 2003, at the Hotel "Wembley Inn" in "Praia das Toninhas" (Toninhas' Beach), Ubatuba, São Paulo.

The conference aims at providing a forum for the presentation of state-ofthe art research in the development, implementation, and real-world applications of statistical models in actuarial sciences and finance, as well as for discussion of problems of current national and international interest in the professional arena. It is open to both academic and non-academic communities from universities, insurance companies, banks, consulting firms and governmental agencies, and specifically meant to contribute to fostering the cooperation between practitioners and theoreticians in the field. Several short courses, round tables, open problems and software sessions are being organized. English will be the official language within the event.

The conference encourages the submission of state-of-the-art surveys, original research papers, work-in-progress reports, future research proposals and students papers. Topics of interest include, but are not limited to:

- Collective Risk Models and Ruin Theory

- Elliptical Distributions and Applications

- Extreme Value Theory and Applications

- Insurance (Life, Non-life, Pension and Health) and Reinsurance

- Risk Measures and Portfolio Selection

- Statistical Analysis of Insurance and Finance Data

An extended abstract of 2 pages should be submitted by e-mailing a PDF-file to ubatuba@ime.usp.br.

It is expected that accepted papers will be presented at the conference. Simultaneous submission to other conferences with published proceedings is not allowed.

\section{Important Dates:}

Submission deadline : April 25, 2003

Notification to authors: May 30, 2003

Final version due : June 27, 2003

Conference : September 1-6, 2003

Observation: Further information and on-line registration will be available on conference web site www.ime.usp.br/mae/ubatuba-conf.html 